



\section{ÔSILK \\ AND THE}

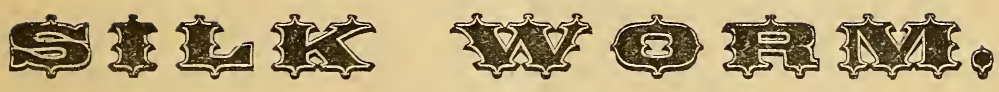

A COMPIETE

\section{BOOK OF INSTRUCTION ON}

\section{SILK CULTURE,}

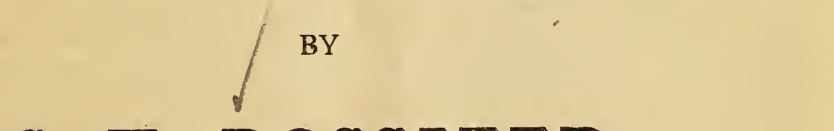

C. F. I 88 I.

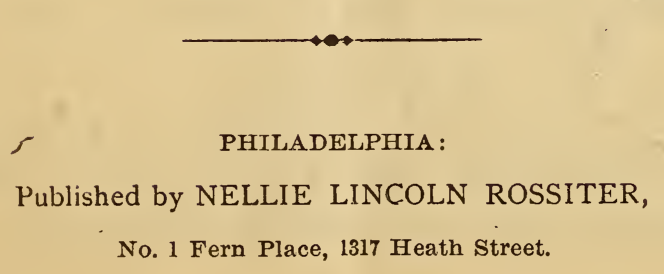
No. 1 Fern Place, 1317 Heath Street.

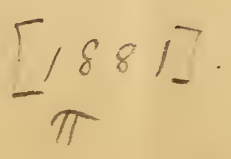





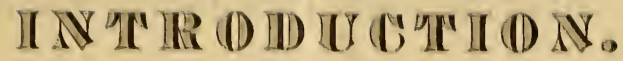

As much has been said in regard to spreading information on silk culture among our people, there seems to be a necessity for doing so in a manner to encourage this industry among those who would be most likely to engage in it -and as ignorance of the means of gaining informationtime and trouble necessary to do so, and the supposed difliculties and expense of statting the work, have no doubt detered thousands from attempting it. I offer this book of instruction, which meets all these difficulties, at a price placing it within the reach of all. I do not wish it understood that I claim the instructions to be entirely original with myself - but I do claim, that from personal experience, and information I have ganed from the best authorities on thrs subject, my instructions, if followed, will enable anyone to raise silk successfully. I hope by this means to encourage and start in the work, those who are not able to spare lime and money for instructions at a school, and those who have no opportunities of visiting places where the necessary information can be obtained. The work contains all the information required for beginners in this beautiful inclustry, which is fast becoming of national importance. I should not venture to introduce it, were it not for the success I have met with by following the rules laid down in it, and the attention I have paid to gain knowledge of the work. My daughter, when not yet $\mathrm{I}_{4}$ years of age, was presented with a "diploma" as a special premium, by the Pennsylvania State Agricultural Society (at their last fair, held in thes city at the Permanent Exhobition Building) for the excellent quality of silk, cocoons, etc., raised by herself.

I take pleasure in referring to the following named gentlemen, Officers of the Association :

PRWSIDENT,

WM. S. BISSEll, Esq., Pittsburgh, Pa.

IICE-PRESIDENTS,

DR. ALFRED L. KENNEDY, Philadelphia.

WM. H. HOLSTEIN, Esq., Montgomery Co., JOHN McDOWELL, Esq., Washington Co., Pa. 


\section{A BOOK OF INSTRUCTION}

\section{$-\mathrm{ON}-$ \\ SILK CULTURE,}

\section{Compiled from personal experience and gathered from the best authorities.}

THE WORM.

The "Bivoltin," or two crop Silk Worm (Bombyx Mori) which in this country supplies the silk ordinarily used in commerce, and is often called the "Mulberry Silk Worm," is produced by a cream.colored moth, with brownish markings more or less distinct across its wings. This moth is called, scientifically, "Sericaria Mori." This worm gives two crops of silk each season, and by following the directions given in this work-with strict attention to details, success will follow.

The great secret of success in raising silk is, first, have plenty of food for your worms; for if not well fed they will not thrive, nor give silk in large quantities or of good quality. And second, even with plenty of food at command, if the worms are not properly attended to, fed as often as they require to be, and strict attention paid to cleanliness, your time and labor will be thrown away. These points it will be well to pay attention to.

THE EGG.

The eggs of the Moth, called by raisers the "seed," are nearly round and very small in size. When first laid they are yellow, and if they retain this color they are worthless. If, however, in 12 or 15 days they change to a darker color (gray or slate), it shows they are impregnated and are good for seed. They also become slightly indented, and are fastened to the card on which they are laid by a natural gum produced by the moth. As the hatching time approached, the egg becomes lighter in color, its fluid contents becoming concentrated in the centre where the worm is forming, leaving the space between it and the shell transparent. Just before hatching the worm becomes active, sometimes producing a faint clicking sound. After it has hatched, the shell becomes quite white. All eggs not hatching by the 4th day from the appearance of the first worms, had better be thrown away, as they are probably sickly or diseased. 
THE BIVOLTIN.

The color of the newly hatched worm is black or dark gray, and it gets gradually lighter till the last age, when it is of a cream-white color. The worm passes through from three to four " molts" or sicknesses. The periods between these molts are called "ages"-there being five of these ages including the first, from the hatching, and the last, from the 4 th molt to the spinning period. The time between these molts is usually divided as follows - the first period, from 5 to 6 days - the second, from 4 to 5 days -the third, about 5 days - the fourth, from 5 to 6 days-and the fifth, from 8 to Io days. These periods are not exact but proportionate.

The time from the hatching to the spinning of the cocoons will vary from 30 to 40 days, depending on the race of the worms, quality of food, mode of feeding, temperature, etc., but the same proportion of time between the molts is generally found to be the same.

When molting is about to take place the worm ceases eating, at which time it firmly fastens iiself by its hinder legs-raises the fore part of its body, and remains motionless for about 12 hours when it casts its skin. During this time it must not be disturbed.

When ready to molt the worm becomes of a dirty yellow color, and care must be taken not to mistake them for the sick worm, which it somewhat resembles, and which will be described hereafter. In front of the first joint a dark spot is to be noticed at this time, showing the growth of the new head, and when this sickness or molt is over and the worm casts off its old' skin, it rests for a short time to recover its strength and then commences eating voraciously, as if to make up for lost time. In molting the new head is just freed from the old skin, which is then gradually worked back until it is entirely cast off. This process is repeated until the 4 th molt, after which, in the course of 8 to Io days' feeding, it will be ready to spin.

All worms hatched on the first two days should be kept together and called the Ist hatçh-those of the third day, the $2 \mathrm{~d}$ hatch-and all the remainder, the $3 \mathrm{~d}$ hatch. This is to have your worms grow up together of an average size, so as to molt at one time, and not to have the larger ones crowding the smaller from their food. It is also advisable to separate the larger worms from the others as they outgrow them.

\section{THE COCOON.}

The "Cocoon" is tough and compact, and is composed of a continuous thread of silk which is strong and firm, and is spun by the worm in figure of 8 , shaped loops. Its shape is generally oval or egg-shaped, and varies in color, the commonest of which are the yellow, straw or cream color, white and green. These colors are supposed to denote the nationality of the worm spinning them. The larger sized rounder-formed cocoons denote the females, while the males are more slender shaped, depressed in the centre 
and pointed at both ends. This is generally used as a rule among growers. The outer lining of the cocoon is a loose silk spun by the worm when preparing for its final work. It is called flock, or floss, and sells with the pierced cocoons and other waste silk. This cannot be reeled, but is carded and spun by the manufacturers. The cocoons will run all the way from 200 to 600 yards. The better the worms are fed and the more care there is taken of them, the heavier and finer the cocoons will be, and the fewer it will take of them to produce a pound of silk.

THE мотн.

The "Moth," which does not eat and which is said to have no jaws, is provided with a liquid secretion with which it moistens the end of the cocoon and dissolves the gum by which the worm fastens its threads of silk together. It then slowly forces its way out, pushing the threads aside; but breaking so many of them as to render the cocoons from which they escape useless for reeling. These are called "pierced cocoons."

\section{FEEDING AND RAISING}

The room in which the worms are to be raised must be arranged so as to allow it to be thoroughly and easily ventilated, and warmed if necessary -one facing the northeast is best. If buildings are erected expressly for the purpose, they must combine all these. If only a small number of worms are to be raised, a few trays placed on tables will be a!l that will be required. If, however, large numbers are reared, frames and trays must be provided -the wood, in all cases, to be well seasoned. Make upright frames across the room, to hold the number of trays to be used to accommodate the worms raised. The worms must not be huddled too closely together, as they need plenty of room for feeding and ventilation. If too many are kept together in the trays, they cannot feed properly-it is more difficult to change themand it also tends to create disease among them. The trays are formed of thin frames like laths, set edgeways-say 16 inches by 24 inches (this will be a good size for handling easily). Drive tacks half way in, on the under side of the frames, all round, about half an inch apart. Then take good strong twine, not too thick, run it from tack to tack lengthways of the frame stretching it tightly-then crossways, interlapping it so as to make a firm support for the musquito-netting, leaves and worms. After stretching the twine on the frame, drive the tacks in to the heads and the tray is complete. A tray of this size will hold and feed 1000 worms at ist and $2 \mathrm{~d}$ age, after which time they must be separated as they grow larger, placing them on other trays. Have musquito-netting (white) cut so as to nearly fit the trays-providing enough to have changes every day which must be attended to, as cleanliness is actually necessary for the health of the worms. Change them early in the morning-and hang the nettings used over night, up ta air. When the worm is first hatched, tarleton is used in place of netting, 
(the meshes of which are too large) on this sprinkle some fresh, tender mulberry leaves. The little worms will leave the eggs and immediately commence eating, and from this time constant attention must be paid to renewing the leaves as.often as may be required-and as the worms eat fast, and the leaves dry rapidly, they need replenishing often. A large quantity of food given at a time is not beneficial, but is a waste. Give the worms what they require for the time and renew as often as they need it.

There have been rules laid down for feeding at certain hours through the day, but these are not to be depended on. The raiser can see when fresh food is needed, and the worms will soon leave the food they do not like. This is why so much attention is required-not that they must be constantly watched, for unless a very large number is being raised, the attendant can, provided they are not away too long at a time, attend to other duties. During the last few days before spinning (5th age) more constant attention is required, as the worms eat enormously. All litter and excrement must be often removed, and the attendant must be on the watch for sick and diseased worms, which must be immediately removed-and food must be on hand in large quantities. The greatest care must be taken to have the worms of the same ages kept together on the trays, so that they will molt at the same time; thus saving much time. They grow rapidly after each molt, and must be separated when necessary to allow them plenty of room. The worms eat most freely early in the morning and late at night; therefore furnish food abundantly between 5 and 6 o'clock in the morning and about II o'clock at night. Leaves for the early morning meal should be picked the day before, as they are apt to induce disease if fed to the worms with the dew on them. When picked during a rain they should be thoroughly dried before using them for food. Damp or wet leaves should never be used, and dried up and withered or stale leaves the worms will not eat-thus the leaves must be fresh picked from the trees as often as possible. If the leaves have to be brought from a distance and cannot be picked fresh every time the worms are fed, place the ends of the twigs or stems in water-keep in a cool, shady place (a cool cellar is best) and renew the water often. The smooth leaves are the best, as the worms do not like the rough ones, though both kinds may be found on one tree.

When changing in the mornings place the netting over, or on top of, the leaves and worms in the trays-sprinkle fresh leaves on it, and the worms will come up through the meshes to feed. When all are up, take the netting carefully by the ends and place on another tray. The old dried leaves and refuse should then be thrown away and the netting shaken clean and aired for another day's changing The netting obviates the handling of the worms almost entirely, which is hurtful to them. If the leaves are given to the worms on the twigs or branches they keep fresh longer, besides having a free circulation of air through them. 
The direct rays of the sun must be avoided, as it will kill the worms. A direct current of air on them is hurtful, but thorough ventilation is necessary. A uniform temperature of $75^{\circ}$ is required for the feeding room. It is not desirable to get it above $80^{\circ}$. Sudden changes from warm to cold or vice-versa should be avoided. The air should be kept pure. If the temperature falls below $70^{\circ}$ artificial heat must be used. If the weather is very hot and dry, sprinkling or mopping the floor two or three times a day will prevent the leaves drying too rapidly and will afford all the necessary moisture the worms require. Be careful in feeding not to allow any other leaves to be mixed with the mulberry, and see that the leaves are clean. A peach leaf has been known to kill the worms eating it. Tobacco in any shape is poison to them. Great care must be taken at all times to prevent birds, ants and insects of all kinds, gaining access to the worms. Rats and mice are always watching for a chance to get at them, all through their existence, and are almost as great an enemy as the silk worm has. The worm when ready to spin will leave its food and search for a place to deposit its silkclimbing as high as it can to do so. Small branches or twigs may be tied together and placed ready for the worms. (See "Spinning.") When ready to spin, they must not be disturbed or handled if it can possibly be avoided. Should two or more of them commence spinning together, making what is called a double cocoon, one of them should be gently removed. The double cocoon cannot be reeled; though the moths from them are perfectly good for laying purposes.

\section{SPINNING.}

Within 8 to ro days after the last molt the worms begin to lose their appetite, become restless and commence throwing out silk. The twigs, etc., should now be prepared for them. Set branches 2 or 3 feet long up in the arches in the trays, about I foot apart at the bottoms. Interlace the twigs with broom coin, hemlock or other well dried brush. Paper cones can also be made and placed among the branches and in the netting. Keep the temperature of the room now at, or about $80^{\circ}$, as the silk flows from the worm much more freely in a warm atmosphere. The worms will climb into the branches and commence spinning. Those that do not, must be still fed often, but in small quantities to prevent waste, as some of them will quit eating and wander away to spin every few minutes. Those that do not commence spinning when the majority have done so, must be moved to another tray, as the worms already mounted will discharge a soft excrement before beginning to spin, which will stain the cocoons below them. In 2 or 3 days the spinning will be completed; and in 6 or 7 days the chrysalis will be formed. 


\section{GATHERING THE COCOONS.}

In 8 days time from the commencement of the spinning it will be time to gather the cocoons. The stained cocoons should first be removed and laid aside. Be very careful not to stain the clean ones with the black fluid of worms that have died-for this will happen in every cocoonery.

The loose outer or floss silk must then be picked off from the inner solid cocoon, which process is called stripping, and the latter separated according to weight, color and firmness-those which feel most solid and resist pressure, being the best. Soft or imperfect cocoons must be separated from the firmer ones, as they would be crushed and soil the others. The finest and firmest must now be taken for seed for the next crop, as it is preferable to keep the eggs, to buying from large establishments-as they are apt to be untrustworthy. It is always best for silk-raisers to provide their own seed. The cocoons for seed must be chosen for their firmness, and the fineness and color of their silk, rather than for size. If whitetake the purest white. If yellow, the straw color is considered the best. If green - the darkest, glossiest ones must be chosen, as these have the best quality of thread. Do not use the pale shade of green cocoon for seed. Should there be any double or treble cocoons-that is, those made by two, or more worms; if they are of the right color and quality use them for seed, for which purpose they are just as good though unfit for reeling. Should it be desired to have an ounce of seed, or 40,000 eggs for the next crop or for sale, it would be safe to take at least 200 cocoons, half male and half female, and even 225 would be safer. Each female moth it is estimated will lay from 200 to 400 eggs.

The cocoons must now be laid aside, awaiting the appearance of the moth-care being taken to keep them from rats and mice. Then take care of the other cocoons which must all be stripped, and they are then ready for stifling or choking.

\section{CHOKING OR STIFLING COCOONS.}

If the cocoons can be sold immediately on their completion, or before the 8th day from their commencement, no further trouble will be necessary after stripping them, than to pack them in bales and ship them to their destination. If the raiser intends reeling-or if some time must elapse before the cocoons can be sold or sent to a reeling establishment or "filature," some means must be taken to prevent the moth from leaving the cocoon, thus injuring the silk for reeling purposes. This can be done by stifling them with steam or choking them with dry heat. Steaming is said to be the surest and quickest method if conveniences are at hand. It can be done at any steam mill. The cocoons are placed on shelves in an air-tight box, and steam turned into it. Twenty minutes will do the required work. and the cocoons are then dried in the sun. Dry-heat choking takes 
a longer time. Place the cocoons on shallow dishes on iron frames in an oven, heated to a temperature of about $200^{\circ}$. This should not be increased for fear of scorching the silk. The operation takes about one hour-though one and a half hours are not too long to insure success. A slight humming noise in the cocoon may be heard while there is life, and its cessation shows that the chrysalids are clead. After this operation is completed, the cocoons should be spread on shelves, in the shade with plenty of air, and be frequently stirred for the first few days. After remaining on the shelves for a few weeks with occasional stirring, the chrysalids become quite dry and the cocoons will keep for an indefinite time. They are still subject to attacks from rats, mice and insects, which are attracted by the dead chrysalis within. After thoroughly drying, place the cocoons in bags of thin material and hang them up for future use.

\section{EGG-LAYING OR REPRODUCTION. \\ Second Crop.}

From the Ioth to the 20 th day from the time when the worm commences to spin, the Moths will begin issuing from the cocoons set apart for breeding purposes. They make their appearance in the greatest numbers in the morning early, from 4 to 8 o'clock-and as they appear should be taken gently by the wings, placed on paper, and the sexes kept apart for a short time. The males may readily be distinguished by their smaller bodies and by the incessant fluttering of their wings. The females remain quiet, their abdomens being distended with eggs. When they first issue from the cocoon they are wet - their wings clinging to their bodies. They soon dry themselves, however; and after being separated for an hour or two, the sexes in equal numbers may be placed together upon paper or card-board, and the room be kept as dark as possible. For the complete impregnation of the eggs the sexes should be kept together 6 hours-neither more nor less, and they should be occasionally visited, in order to replace the males which may have become separated. Should more males than females issue from the cocoons on any day, the superfluous males may be put in a closed box and kept till the next day. Should there, on the other hand, be more females than males, a sufficient number of the most vigorous males should be uncoupled at the end of 4 hours and placed with the uncoupled females for 6 hours more. When separated great care must be taken not to injure the moths. The female should be held by the wings with one hand and the abdomen of the male be gently pressed with the other. The males may then be laid aside in a box, as there may be use for them before all the moths have appeared. After all the females have been impregnated the males may be thrown away. The females as soon as separated should be placed for a few minutes upon blotting paper, where they will discharge a quantity of greenish-yellow fluid. From this they should be put on the 
cards placed upon trays, on which the eggs are to be laid. Some raisers prefer a sort of smooth woolen cloth for the moths to lay on. It is advisable to tip up the trays at one end, as it enables the moths to lay their eggs uniformly. The temperature of the room should be kept at $75^{\circ}$ and plenty of air given during their laying. Keep the room dark till laying is finished. The moths may be removed in about 24 hours, as by that time all the thoroughly impregnated eggs will be laid. Any eggs laid after that time must be separated from the others. The eggs are fastened to the card or paper on which they are laid, by a natural gum, produced by the moth while laying, and it is best to use these cards with care, so as to preserve the eggs, which being fastened, the young worms eat their way out better. The eggs retain a light-yellow color for 12 or 15 days when they gradually change to the gray, lavender or greenish tint, which shows them to be impregnated. Those which retain their original color longer than this, are generally worthless. The moths live but a few days after laying. They do not eat anything during their short lives.

\section{ENEMIES AND DISEASES.}

The silk worm has its enemies and diseases. The former it can be protected from; but for the latter there are no remedies which are of any use. Its worst enemies are rats, mice, ants and birds. Rats and mice are the most persistent ones. By keeping the windows and doors covered with netting or fine wire screens, the birds can be kept away. The others must be watched for and destroyed. For diseases-the best and safest plan is to immediately remove and destroy all sick worms, to protect the rest of the crop from infection. One disease called "muscardine" is very destructive. The worm becomes languid, suddenly dies, and in a short time becomes stiff and discolored-in about a day a kind of white powder shows itself, and soon covers the body. No outward signs indicate the first stage of this disease, and though it attacks worms of all ages, it is most destructive and fatal in the last age just before spinning. No remedy is known for it. Good eggs, good leaves, a pure, even temperatured atmosphere, care in rearing the worms, and cleanliness, are checks to it. It is advisable once in a while to wash the trays and frames with "diluted carbolic acid." This is the best disinfectant known, and is a sure preventive of disease. Another disease called "pebrine," has for years been a scourge among silk worms in France. The worms affected by it grow unequally, become languid, lose appetite and often show discolored spots upon the skin. They die of it at all ages, but most at the last age. The worms will be purged by eating unwholesome leaves. Too great heat will make them sickly. If the worm becomes yellow, limp and soft, it is caused by a disease called "grasserie" or "jaundice," which is very common in those raised in this country. When worms die from being unable to molt, they are called "lusettes"-these cases are 
most common at the $4^{\text {th }}$ molt. These diseases need not become too troublesome or serious if proper care and attention be given to the worms.

\section{VARIETIES OR RACES.}

The different varieties of Silk Worm have been produced by domestication; the different climates into which it has been carried having effected changes in the habits of the worm, the shape and color of the cocoon, or the quality of the silk. There are different varieties of the silk worm. The "Annual," which producess only one crop of silk in a year-the "Bivoltin" or "2-crop worm," of which this book treats, which, like the "Annual," hatches in April or May; and which unlike the Annual, again hatches for a second crop in $\delta$ to 12 days after the eggs are laid by the first brood. The eggs of this second brood are always laid away for the next spring crop; for if hatched they would not live, there being no food for them so late in the season, and the weather being unfit to rear them. "Trevoltins" produce three annual broods. There are also "Quadrivoltins;" and in Bengal a species known as "Dacey" is said to produce 8 broods in the course of a year. Some varieties molt only three times instead of four-especially in warm countries-as also do the "Trivoltins." Varieties are also known by the color of their cocoons, "greens, whites and yellows," and also by the country in which they best flourish. The three most noted varieties are "Italian," producing fine, small yellow cocoons. "French," producing large yellow and straw-colored cocoons. "Turkish," producing large white cocoons, and the "Japanese" white and green, and the "Chinese" white cocoons. Some of these are "annuals," but the different colored cocoons are generally called by the above names. The silk of the "white" cocoons is the most valuable in commerce, but the "straw-colored" is most sought after. The races producing the yellow and straw-colored cocoons are considered the most vigorous.

\section{WINTERING AND HATCHING.}

The importance of having the eggs free from disease and of good races, has already been shown. They should be kept in tin boxes to prevent the ravages of rats and mice, and be hung by string or wire from a joist in cool, dry cellar where the temperature rarely sinks below the freezing point. They should be occasionally examined to see if they are affected by mold. If this should be discovered on them, it must be carefully rubbed or brushed off them at once, and they should be put in a drier place. The tin boxes may be perforated on two sides and the holes covered with fine wire netting. The temperature should never be allowed to rise above $40^{\circ}$, but may fall to freezing point without injury to the eggs. They should be kept at this low temperature till hatching time, which will be when the mulberry leaves are about one and a quarter inches in length (middle of April to May Ist) and great care must be taken as the warm weather in- 
ereaces in the spring, to prevent their hatching before the leaves are ready for them. When the warm weather commences, if too early for their food, enclose the tin box in a wooden one, and place it on ice. As the tendency in our climate is to premature hatching, the great object is to keep them all back, as described above, till their food is plenty. When the proper time arrives, the eggs should be brought out gradually from the cold cellar at $40^{\circ}$ to a room at $50^{\circ}$ for one hour ; then to a room at $60^{\circ}$ for half an hour, and then to hatching room at $75^{\circ}$. Then use the "tarleton" netting, and proceed as described in "Feeding and Raising," Keep the temperature as uniform as possible, and if it is increased about 2 degrees each day it will hasten the hatching of the eggs. As the time of hatching approaches the eggs grow lighter in color--and if the floor is sprinkled, to moisten the atmosphere, it will enable the worm to eat through the shell more easily. A small amount of moisture appears to freshen and invigorate them. The eggs should be brought out about $4 \mathrm{p}$. $\mathrm{m}$., or the cool of evening, as the worms hatch out from 4 to 8 o'clock in the morning.

SUMMED UP.

The requisites for success in raising Silk Worms are-

Ist.-Having good, healthy eggs.

2d.-Having the worms as nearly as possible of the same age in the same trays, to insure their molting at the same time.

3d.-Feeding regularly and plentifully as it is needed by the worms.

4 th.-Plenty of room so that the worms do not crowd each other.

5th.- Fresh air and uniform temperature.

6th.-Cleanliness.

The last three are actually necessary during the $4^{\text {th }}$ and $5^{\text {th }}$ ages. Never allow the trays to go one day without cleaning, particularly during the above named ages, or the worms will suffer in disease or death just as they are about spinning. Should there be repetitions found in this work, it will be only in cases where the learner's attention is to be particularly called to important items.

\section{FOOD PLANTS.}

The usual food for the silk worm is the mulberry-the "white" being the best and the "purple" the next. The "black" and "paper" mulberry are not good food for them and should be avoided. The mulberry grows readily and is easily propagated by cuttings or from seed. The white in particular grows well from cuttings, and is the most economical and quickest mode of planting to secure a stock. The cuttings must be started in rows, 3 or 4 inches apart, after preparing the ground by deep plowing and harrowing. They should be about 6 inches long, and in every case must be cut before the eye. They must be almost entirely buried. The quickest way to get a supply of leaves is by dwarfing-setting out the young trees 
from the nursery in rows io to 15 feet apart, and 6 to 8 feet between the rows-from the top of the tree by cutting down to a foot from the ground. The height and form of the tree are regulated by pruning, and the vigorous growth of the tree and the ease with which the leaves can be gathered depends on this process. Pruning should be done in February or March, either every, or every other, year. Remove all dead twigs and dried bark, and keep the limbs as smooth as possible. Plant in the fall from frost till December, and in the spring from March till May. The following directions are from a practical raiser for growing standard trees: The cuttings should remain in the nursery 2 years without pruning. The $3 \mathrm{~d}$ year cut close to the ground and transplant. Allow the finest shoot to grow, and if the land is good it will grow 8 to 10 feet in height in one season. The 4 th year cut it back to about 6 feet. Then allow the 3 or 4 terminal buds only to grow, removing the others as often as they appear, by passing the hand along the stem: The "Morette," a variety of white mulberry, is profitably grown in hedges. It is very desirable on account of the large size of its leaves. The cultivation of the Osage Orange is well understood in this country. As it is generally used as a hedge in those parts of the country which are specially adapted to silk culture, the leaves may be readily obtained, and as the hedges need trimming, the cutting off of the new growth each year as the leaves are wanted for food, is a saving rather than an expense. Those using this plant for food for silk worms must remember that as the shoots from a hedgerow become more vigorous, milky and succulent by the time of the last age of the worms, the terminal leaves should not be used but thrown aside, as they are likely to induce disease. If care be taken in this respect there will be no apparent difference between the silk crop and that of the mulberry. Should the worms from any cause hatch before either Mulberry or Osage Orange leaves can be obtained, they may be successfully fed for a few days on well dried "lettuce leaves"-but it is worse than a useless waste of time to attempt feeding them entirely on these, or the leaves of any other plants than the two here recommended.

\section{REELING.}

The reeling of the silk is by no means a simple operation, as the greatest skill is required to do the work properly ; and the value of the silk depends as much on the skill of the reeler, as upon its original quality. The thread of silk as it unwinds from the cocoon, is of no value for manufacturing purposes-as several of them must be combined to make the staple silk of commerce. Where there are steam-reeling establishments or "filatures" it is more profitable to sell the cocoons or have them reeled there, than to have the trouble and expense of reeling by hand with the chances all in favor of the silk after all not being marketable. There are probabilities of "filatures," being erected in this country during the coming season, which 
will be duly published in the newspapers. The cocoons can be sent to those places and sold, or the silk reeled at a small cost. In the meantime reelers will be trained, who will impart the necessary knowledge to others.

Raw silk is divided into three classes, "organzine," "tram" and "floss." "Organzine" is well twisted and is the choicest; "tram," made from inferior cocoons, is but slightly twisted; "floss" is made from loose silk carded and spun like cotton. The persons reeling silk are generally women, one of whom sits or stands before each basin of which she has entire charge. The basin is made of tin or copper, heated by a charcoal or oil fire. In large establishments the water is heated by steam.

The cocoons are plunged into the water when it is near the hoiling point, and moved about so that the gum which fastens the threads is thoroughly softened. They are then stirred or beaten with a small bunch of birch twigs with split ends, or with pieces of broom corn tied in a bunch, to which the ends of the threads will attach themselves. The reeler will then shake the cocoons till each one hangs by a sing'e thread. She now takes up five or more threads, according to the quality of silk wanted, unites them, and puts the combined strand through a little glass eye, or large glass bead, fastened on one side of the reel-frame. She then forms a similar strand and puts it through another eye on the other side. The strands are then brought together, twisted several times, separated above the twist and put through two other glass eyes or wire loops through which they run one to each end of the reel, which is kept revolving in a steady, rapid manner, and to which is given a side-way motion which crosses and re-crosses the silk in such a manner that it will not stick or glaze. The uniformity of the thread depends entirely on the skill of the reeler, who must attach a new thread as soon as one breaks or a cocoon gives out. This is called nourishing the silk and is done by dexterously attaching the new thread to the combined strand to which it immediately adheres. In this much judgment must be used, for as the silk on a cocoon gets lighter and finer as it nears the end, the uniformity of the strand does not entirely depend on the num. ber of individual threads forming it. When the silk comes off the cocoon in bunches the water is too hot; when it unwinds with difficulty it is too cold, and it must be regulated as the operator sees it is necessary. This is the operation of reeling, but before the skeins as they come from the reel are ready for the manufacturer, they must be passed through a cleanser-a clasp lined with cloth which catches any loose silk or other matter adhering to it. It is further cleansed by being passed through four similar cleansers, twisted about 500 times to the yard, doubled and again twisted 400 times to the yard. It is finally run on reels about one and a half feet in diameter-then taken off and twisted in knots or hanks in a peculiar manner. Through all these operations the oscillating motion is continued, to produce the 
crossing of the strands. In the end it will be seen that it takes ten or more of the simple threads spun by the worm to compose the staple thread. The loose, "flock" silk, together with all that cannot be reeled, is soaked in water for three days, boiled in clear lye for half an hour, washed in rain-water, and, when dry, is carded and spun. This shows that it would hardly be safe for individuals to reel their own silk.

CONCLUSION.

In conclusion, I would state that there is a market at Marseilles, France, for choked cocoons, which can be packed in bales about 5 by 6 feet in size, which average about 40 pounds, and shipped there at a rate of freight costing $\$ 3.00$ per hundred pounds. As high as $\$ 2.50$ net, has been obtained for them there. Eggs raised in this country, which are generally free from disease, have been sold from $\$ 5.00$ to $\$ 8.00$ per ounce.

As in taking the lowest estimate, 200 cocoons, half male and half female, will give 1 ounce, or 40,000 eggs, which are marketable now at $\$ 5$ per ounce, it will be seen that this branch of the business is profitable. Whole choked cocoons, at $\$ 1.50$ to $\$ 2.00$ per pound, and pierced cocoons and flock silk at $\$ 1.00$ to $\$ 1.50$ per pound, will add to the profit, so that in the whole, silk-raising will give a very good return for the very small expense and the labor and care involved. It will add to the income of thousands of families in the United States by giving light and easy employment for a few months each year to the aged, the young, and particularly to the women of the family, who have no other profitable employment for their time.

Any further information which may be required I will cheerfully give. Address, with stamp enclosed,

$$
\text { C. H. ROSSITER, }
$$

No I Fern Place, r3I7 Heath street, Philadelphia, $\mathrm{Pa}$. 

LIBRARY OF CONGRESS

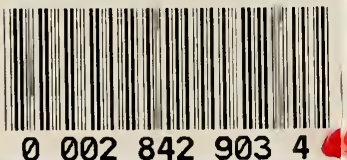

